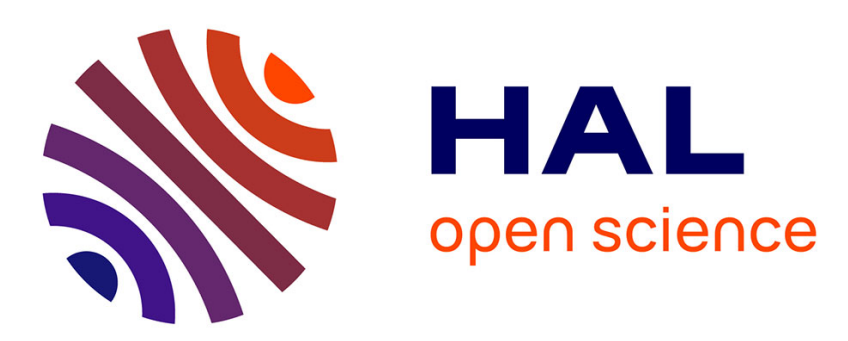

\title{
Temperature Control of Sequential Nucleation-Growth Mechanisms in Hierarchical Supramolecular Polymers
}

Artem Osypenko, Emilie Moulin, Odile Gavat, Gad Fuks, Mounir Maaloum, Mark Koenis, Wybren Jan Buma, Nicolas Giuseppone

\section{- To cite this version:}

Artem Osypenko, Emilie Moulin, Odile Gavat, Gad Fuks, Mounir Maaloum, et al.. Temperature Control of Sequential Nucleation-Growth Mechanisms in Hierarchical Supramolecular Polymers. Chemistry - A European Journal, 2019, 25 (56), pp.13008-13016. 10.1002/chem.201902898 . hal-03080480

\author{
HAL Id: hal-03080480 \\ https://hal.science/hal-03080480
}

Submitted on 18 Dec 2020

HAL is a multi-disciplinary open access archive for the deposit and dissemination of scientific research documents, whether they are published or not. The documents may come from teaching and research institutions in France or abroad, or from public or private research centers.
L'archive ouverte pluridisciplinaire HAL, est destinée au dépôt et à la diffusion de documents scientifiques de niveau recherche, publiés ou non, émanant des établissements d'enseignement et de recherche français ou étrangers, des laboratoires publics ou privés. 


\title{
Temperature Control of Sequential Nucleation-Growth Mechanisms in Hierarchical Supramolecular Polymers
}

\author{
Artem Osypenko, ${ }^{[\mathrm{a}]}$ Emilie Moulin, ${ }^{[\mathrm{a}]}$ Odile Gavat,${ }^{[\mathrm{a}]}$ Gad Fuks, ${ }^{[\mathrm{a}]}$ Mounir Maaloum, ${ }^{[\mathrm{a}]}$ Mark Koenis, ${ }^{[\mathrm{b}]}$ \\ Wybren Jan Buma, ${ }^{[\mathrm{b}, \mathrm{c}]}$ and Nicolas Giuseppone ${ }^{[\mathrm{a}]^{*}}$
}

[a] Dr. A. Osypenko, Dr. E. Moulin, O. Gavat, Dr. G. Fuks, Prof. Dr. M. Maaloum, Prof. Dr. N. Giuseppone SAMS research group, University of Strasbourg - Institut Charles Sadron, CNRS, 23 rue du Loess, BP 84047, 67034 Strasbourg Cedex 2, France e-mail: giuseppone@unistra.fr

[b] Dr. M. Koenis, Prof. Dr. W. Jan Buma, Van 't Hoff Institute for Molecular Sciences, University of Amsterdam, Science Park 904, 1098 XH Amsterdam, The Netherlands

[c] Prof. Dr. W. Jan Buma, Institute for Molecules and Materials, FELIX Laboratory, Radboud University, Toernooiveld 7c, 6525 ED Nijmegen, The Netherlands

\begin{abstract}
Upon cooling in various solvents, chiral triarylamine tris-amide unimers produce organogels by stacking into helical supramolecular polymers which subsequently bundle into larger fibers. Interestingly, AFM imaging, circular dichroism, and vibrational circular dichroism of the chiral self-assemblies reveal that, while monocolumnar $P$-helical fibrils are formed upon fast cooling, bundled $M$-superhelical fibers are formed upon slow cooling. The mechanistic study of this structural bifurcation demonstrate the presence of a strong memory effect, reminiscent of a complex stepwise combination of primary and secondary nucleation-growth processes. These results highlight the instrumental role of pathway complexity to influence sequential self-assembly processes and to control supramolecular architectures of multiple hierarchical order.
\end{abstract}

\section{Introduction}

Supramolecular polymers ${ }^{[1-5]}$ that involve stacking of $\pi$-conjugated molecules are of particular interest to design new materials for organic electronics ${ }^{[6-10]}$ and photonics. ${ }^{[1]]}$ Beyond their molecular structure, the functional properties and efficiencies of such soft materials in devices are strongly dependent on their morphologies at all scales. ${ }^{[2-14]}$ Therefore, the fundamental understanding of supramolecular polymerization mechanisms is of critical importance to get control over the spontaneous structuring processes occurring from molecular level to mesoscale. Efforts from various research groups worldwide are currently showing that supramolecular polymerization can go much further than the simplest isodesmic growth regime, and that it can make use of a number of more complex kinetic pathways for giving rise to highly cooperative processes and thermal hystereses $^{\left[{ }^{15-18]}\right.}$ For instance, living supramolecular polymerization ${ }^{[19-22]}$ and access to supramolecular block copolymers ${ }^{[23-27]}$ were recently demonstrated by precisely engineering molecular structures of monomers and by tuning experimental conditions. In addition, the presence of competing kinetic and thermodynamic self-assembly pathways was shown to potentially bias the expression of supramolecular chirality of one-dimensional helical polymers. ${ }^{[28-30]}$ For instance, Meijer and co-workers have shown the possibility to invert the absolute configurations of helical fibrils made of oligo( $p$-phenylenevinylene) by acting on the primary nucleation step and the subsequent primary growth of single polymer chains. ${ }^{[31]}$ Up to now, these observations have been limited to one-dimensional supramolecular polymers, although one may expect that such pathway complexity could also affect the hierarchical organization of supramolecular polymers comprising stepwise nucleation steps.

We became interested in approaching such systems by using supramolecular polymers made of $C_{3}$-symmetric triarylamine trisamides (TATAs). ${ }^{[32]}$ They were recently shown to present helical stacked structures with a possible hierarchical bundling of their primary fibers up to the formation of organogels. ${ }^{[33,34]}$ From a functional point of view, this new family of supramolecular polymers ${ }^{[35-38]}$ presents unusual electronic, ${ }^{[39-41]}$ photonic, ${ }^{[42]}$ and plasmonic properties. ${ }^{[43,44]}$ In addition, TATA based supramolecular polymers display high cooperativity in the expression of their chirality at the level of the single fibers. For instance, unusually low amounts of enantiopure TATAs can drive the homochiral twisting of monocolumnar helices by a sergeant and soldier mechanism. ${ }^{[45]}$ Even circularly polarized light was reported to switch the helicity of fibers made of non-chiral TATAs. ${ }^{[46]}$ By using chiral side chains to produce i) enantiopure TATAs, ${ }^{[4]}$ i) enantiopure TATAs having reversed amide orientations, ${ }^{[23,48,49]}$ or iii) enantiopure carbonyl bridged TATAs, ${ }^{[50]}$ it was also demonstrated that temperature or solvent can induce an inversion of helicity within the corresponding one dimensional supramolecular polymers thanks to intermolecular rearrangement of the hydrogen bond network.

In the present work, we now investigate for the first time the hierarchical supramolecular polymerization mechanism of $C_{3^{-}}$ symmetric TATAs organogelators decorated either with chiral alkyl chains $\left((\boldsymbol{S})\right.$-TATA) or with achiral ones ((C $\left.\mathbf{C}_{9}\right)$-TATA and $\left(\mathbf{C}_{14}\right)$-TATA) (Figure 1). By a combination of circular dichroism (CD), vibrational circular dichroism (VCD), transmission and scanning electron microscopies (TEM, SEM), and atomic force microscopy (AFM), we show that, intriguingly, the hierarchical supramolecular structure and chirality of the (S)-TATA fibers can be modified by simply controlling the cooling rate of the initial solutions, because of a stepwise combination of primary and secondary nucleation-growth mechanism. 


\section{Results and Discussion}

\section{Synthesis and Characterization of TATA-based Supramolecular Polymers}

(S)-TATA, $\left(\mathbf{C}_{9}\right)$-TATA and $\left(\mathbf{C}_{14}\right)$-TATA were obtained in a few synthetic steps with high yields using straightforward procedures from the literature, ${ }^{[33]}$ and they were characterized by ${ }^{1} \mathrm{H},{ }^{13} \mathrm{C}$ NMR, and ESI-MS spectroscopies (see Supporting Information (SI) Section S1.2). These three compounds were found to spontaneously self-assemble in a variety of organic solvents such as chloroform, toluene, and acetonitrile. A first indication of their self-assembly was revealed by the lack of all ${ }^{1} \mathrm{H}$ NMR resonance signals from the triarylamine core at room temperature, and their further appearance at higher temperatures. ${ }^{[35]}$ For instance, in toluene- $d_{8}$, upon gradual heating (from $25^{\circ} \mathrm{C}$ to $105^{\circ} \mathrm{C}$ ) of a $5 \mathrm{mM}$ solution, the recovery of enantiopure (S)-TATA resonance signals was observed, suggesting a transition from the assembled to the molecularly dissolved states (see SI, Figure S1). Subsequent cooling of this solution to room temperature resulted in the formation of an opaque gel with again the disappearance of the ${ }^{1} \mathrm{H}$ NMR resonance signals. The onset gelation concentration (OGC) for (S)-TATA in toluene was measured around $0.56 \mathrm{~g} / \mathrm{L}(0.75 \mathrm{mM}$, Figure S2). The formation of thermoresponsive physical organogels was also observed in other aromatic solvents as well as in chlorinated solvents, but at much higher concentrations (OGC of $2.8 \mathrm{mM}$ and $9.0 \mathrm{mM}$ in dichloroethane and dichloromethane respectively), while no gelation occurred in polar solvents such as DMSO, DMF, THF or methanol/toluene mixture even at high concentrations (Section S2.2, Table S1). ( $\left.\mathbf{C}_{9}\right)$-TATA and $\left(\mathbf{C}_{14}\right)$-TATA were also found to form thermoresponsive gels in toluene at OGC similar to (S)-TATA ( 0.70 and $0.72 \mathrm{mM}$ respectively).

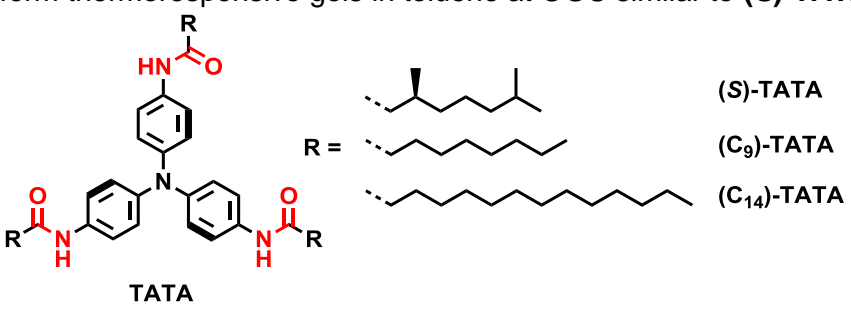

Figure 1. Chemical structures of $C_{3}$-symmetric triarylamine tris-amides (TATAs) that incorporate either achiral or chiral alkyl chains

We then probed the structures of these gels by polarized optical microscopy (POM) at concentrations of 0.1 and $1 \mathrm{mM}$ in toluene (Figures $2 \mathrm{~A}$ and $\mathrm{S} 3$ ). For both of these concentration regimes, i.e. below and above the OGCs of the three TATA molecules, we observed large fibers up to several hundreds of micrometers in length. At $1 \mathrm{mM}$, compared to (S)-TATA, fibers made of $\left(\mathbf{C}_{9}\right)$-TATA appear shorter and more rigid while those made of $\left(\mathbf{C}_{14}\right)$-TATA appear thinner and shorter (Figure S3). The morphology of the fibers was then studied by TEM (Figures 2B and S4) and SEM (Figures 2C and S5). Micrographs show that TATA-based polymers self-assemble into bundles of fibers up to several micrometers in length and up to hundreds of nanometers in diameter. The internal organization of TATA molecules within these self-assemblies was first studied by Fourier Transform InfraRed (FTIR) spectroscopy (Section S2.4). This technique has been widely used to identify and differentiate molecular packing through different types of hydrogen bonds in supramolecular polymers. ${ }^{[3,48,51-53]}$ FTIR spectra of (S)-TATA, $\left(\mathbf{C}_{9}\right)$-TATA, and $\left(\mathbf{C}_{14}\right)$-TATA in both the solid state after the synthesis and after self-assembly from a freeze dried solution (at an initial concentration of $1 \mathrm{mM}$ in toluene) show well-defined bands at around 3290 and $1653 \mathrm{~cm}^{-1}$ corresponding to the stretching vibrations of the $\mathrm{N}-\mathrm{H}$ and $\mathrm{C}=\mathrm{O}$ bonds respectively (Figures $2 \mathrm{D}$ and $\mathrm{S7}$ ). These observations clearly indicate the presence of intermolecular hydrogen bonds between molecules as compared with the frequencies of the free $\mathrm{N}-\mathrm{H}$ and $\mathrm{C}=\mathrm{O}$ stretching vibrations $\left(3500-3400\right.$ and $\approx 1685 \mathrm{~cm}^{-1}$ respectively). ${ }^{[54]}$ The high symmetry of the amide and carbonyl stretching vibrations also suggests the existence of a single type of hydrogen bonds involving a regular columnar packing of the TATAs. ${ }^{[51]}$ In addition, taking into account the MM2 geometry optimization model of (S)-TATA pentamer (Figure S8) and our previously reported DFT calculations on achiral TATAs, ${ }^{[3]]}$ we assign these frequencies to the formation of threefold helical intermolecular hydrogen bonding between neighboring TATA molecules within a single columnar stack. AFM imaging of (S)-TATA at low concentrations $(0.1 \mathrm{mM}$ in toluene) confirmed the formation of thin fibers with a minimal diameter of $1.5 \mathrm{~nm}$ that corresponds to the diameter of an individual columnar stack (Figure 2F). ${ }^{[33,36]}$

The optical properties of all TATA molecules were then studied by UV-Vis and fluorescence spectroscopies (Section S2.5). The general trends observed are: (I) solvatochromism, i.e. bathochromic shift of absorption and emission maxima with solvent polarity (Figure S10A); (ii) temperature-independent emission and absorption spectra at concentrations of TATA below which self-assembly occurs (i.e. $0.01 \mathrm{mM}$ in toluene), (Figures S10 and S17); (iii) at room temperature and at higher concentrations (i.e at $1 \mathrm{mM}$ when self-assembly occurs in toluene) shifting of the absorption and emission maxima towards lower wavelengths together with a decrease of fluorescence intensity and an increase in absorption intensity (Figure S9, Table S2). Such hypsochromic shifts result from $\pi-\pi$ stacking interactions between the aromatic rings of TATA molecules. (S)-TATA was further characterized by circular dichroism in order to provide information on the chirality of its supramolecular structure. ${ }^{[31,55-57]}$ All $C D$ spectra were recorded after a fast cooling of hot solutions of (S)-TATA to room temperature and in different solvents at a concentration of $0.5 \mathrm{mM}$ (Figure S18). The formation of chiral aggregates was demonstrated in solvents such as toluene, xylene, and chlorobenzene.

Having characterized the supramolecular structures of these self-assemblies, we further investigated their mechanism of supramolecular polymerization using different temperature-dependent spectroscopic techniques and mainly focusing on (S)TATA. 

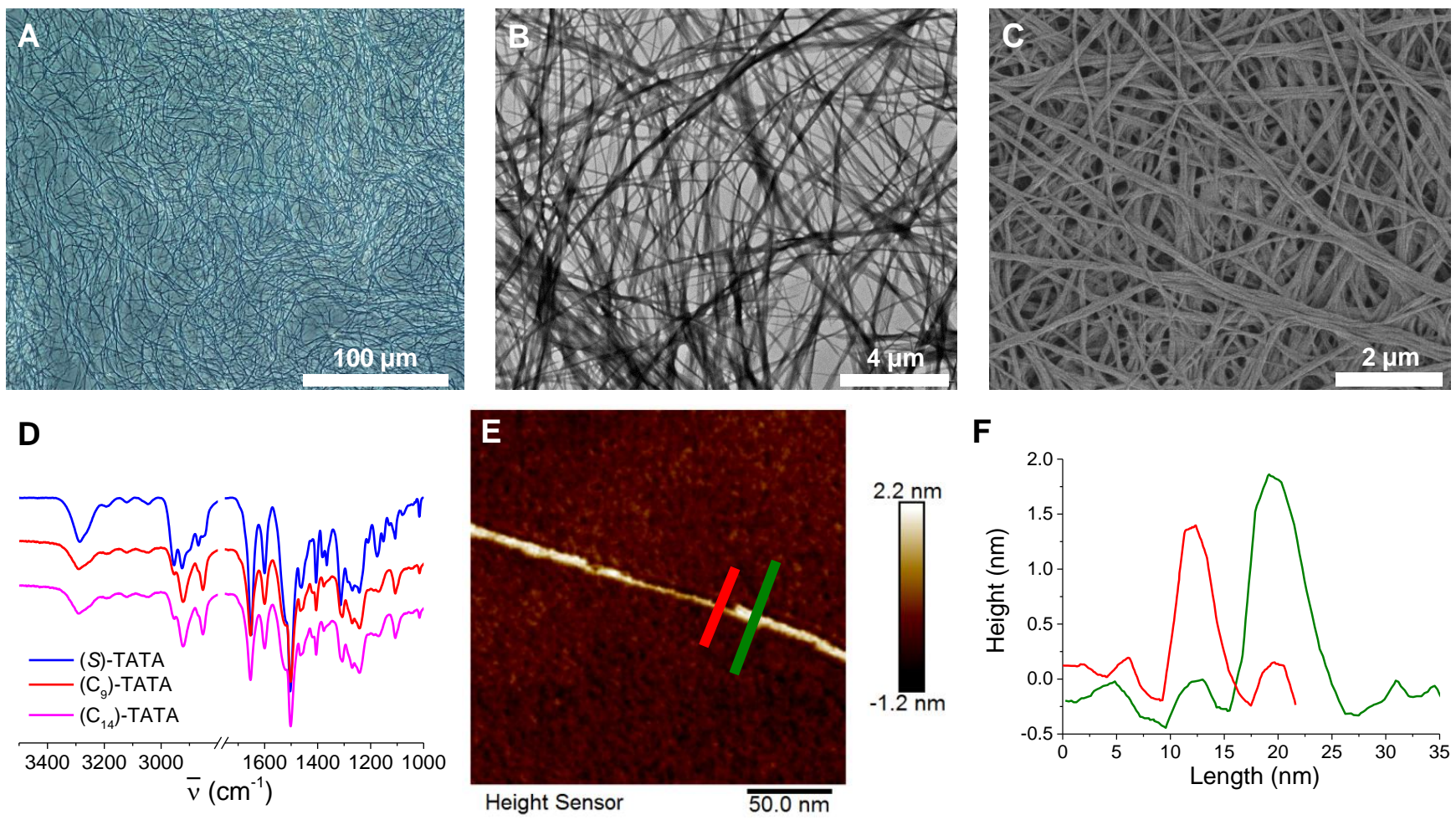

Figure 2. Supramolecular structures of TATA-based supramolecular polymers: (A) POM; (B) TEM; and (C) SEM micrographs of (S)-TATA supramolecular

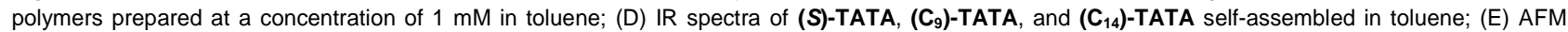
image and $(F)$ corresponding height profiles of (S)-TATA supramolecular polymers prepared at a concentration of 0.1 mM in toluene (the red profile corresponds to a single fiber with a diameter in agreement with molecular modeling).

\section{Study of the Supramolecular Polymerization Mechanism}

Temperature-dependent UV-Vis spectroscopy measurements were performed to investigate the self-assembly mechanism of TATA molecules (see details in Section S2.5.1). ${ }^{[3]}$ Figure 3A shows UV-Vis spectra of a $0.5 \mathrm{mM}$ solution of (S)-TATA in toluene when decreasing temperature from $338 \mathrm{~K}$ to $283 \mathrm{~K}$ (and with increments of $-5 \mathrm{~K}$ ). A decrease in absorption intensity is observed together with a hypsochromic shift of the absorption maximum from $322 \mathrm{~nm}$ to $310 \mathrm{~nm}$. These changes indicate a transition from the molecularly dissolved state to the aggregated state - (S)-TATAAgg. The corresponding cooling trace (Figure 3B) shows a decrease of the absorption intensity measured at $315 \mathrm{~nm}$ with temperature. The non-sigmoidal character of the curve, together with the presence of two temperature regimes, clearly suggest a cooperative aggregation mechanism for the self-assembly process ${ }^{[58]}$ Melting curves $\alpha_{\text {Agg }}=f(T)$ were also obtained by recording the absorption intensity at $315 \mathrm{~nm}$ during the cooling and heating processes at a rate of $1 \mathrm{~K} \cdot \mathrm{min}^{-1}$ for concentrations going from $0.1 \mathrm{mM}$ to $1 \mathrm{mM}$ (i.e. below and above the OGC $(0.75$ $\mathrm{mM})$ ) (Figure S13). These experiments reveal for all concentrations the existence of a thermal hysteresis characterized by a difference between the critical elongation temperature during the cooling process $\left(T_{e}\right)$ and the heating process ( $\left.T_{e}\right)$, thus suggesting the existence of a kinetic barrier in the self-assembly of (S)-TATA during the cooling process (Figure $3 \mathrm{C}$ ). ${ }^{[15]}$ The thermal hysteresis was observed at all cooling and heating rates (Figures S11) and with a decrease of the difference between $T_{e}$ ' and $T_{e}\left(\Delta T_{e}\right)$ when increasing concentrations (Figure 3D). Interestingly, elongation temperatures in both heating and cooling processes increase with concentrations, thus confirming that (S)-TATA molecules follow a highly cooperative polymerization process in toluene (Figure S13). Fitting the melting curves in the heating process with models of unidimensional supramolecular polymerization optimized by Meijer and co-workers ${ }^{[59]}$ confirmed the cooperative mechanism (Figures S12, S13 and Table S3). ${ }^{[58]}$

For instance, we determined an elongation enthalpy $\Delta H_{e}$ of $-66 \pm 1 \mathrm{~kJ} \mathrm{~mol}^{-1}$ and a critical elongation temperature $T_{e}$ of $313.8 \mathrm{~K}$ at a concentration of $1.0 \times 10^{-4} \mathrm{M}$. Over the range of concentrations studied, $T_{e}$ ' decreased linearly according to the Van 't Hoff plot (Figure 3E). For (S)-TATA in toluene, the standard enthalpy change $\Delta H^{\circ}{ }_{e}$ and the standard entropy change $\Delta S^{\circ}{ }_{e}$ for the elongation process were estimated to be $-72 \pm 1 \mathrm{~kJ} \cdot \mathrm{mol}^{-1}$ and $-153 \pm 4 \mathrm{~J} \cdot \mathrm{mol}^{-1} \cdot \mathrm{K}^{-1}$ respectively, leading to an elongation equilibrium constant $K_{e}$ of $4.0 \times 10^{4} \mathrm{M}^{-1}$ at $298 \mathrm{~K}$ (Figure S14 and Table S4). The enthalpy values determined by temperaturedependent $\left(\Delta H_{e}^{\circ}\right)$ and concentration-dependent $\left(\Delta H_{e}^{\circ}\right)$ experiments are quite close to each other, and also similar to the one recorded for self-assembling triarylamines having reversed amide moieties $\left(-77 \mathrm{~kJ} \mathrm{~mol}^{-1}\right) \cdot{ }^{[48]}$ Overall, these data support the fact that the supramolecular polymerization of (S)-TATA in toluene occurs through a cooperative nucleation-growth process. Such cooperativity in the stacking of TATA molecules is not surprising, as nucleation requires to stop the internal rotations and to flatten the conformation of these molecular propellers. 
A

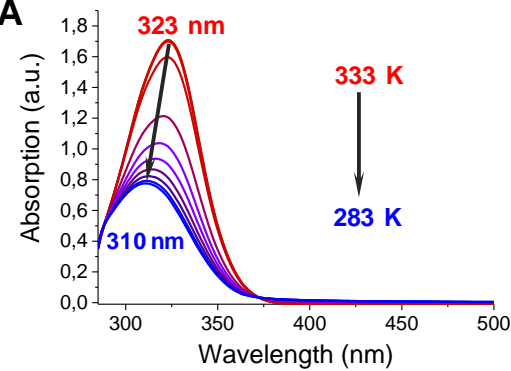

D

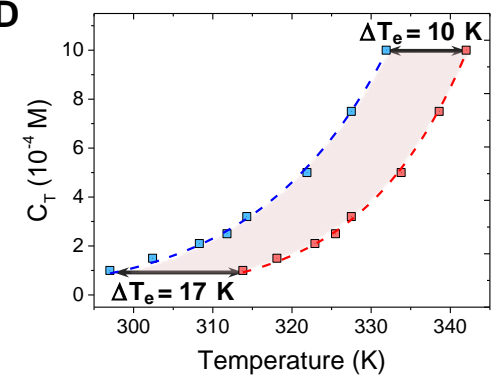

B

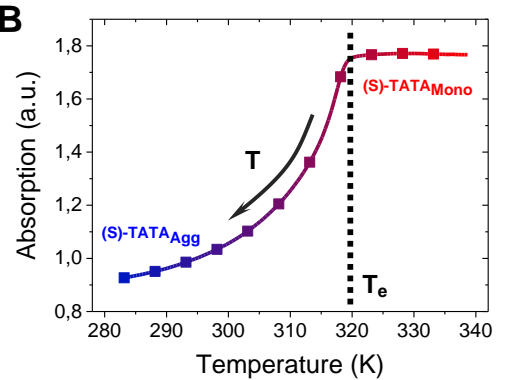

E

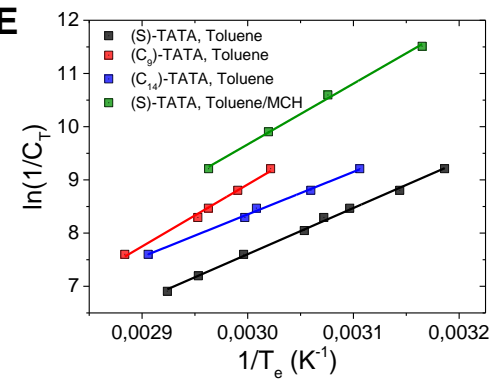

C

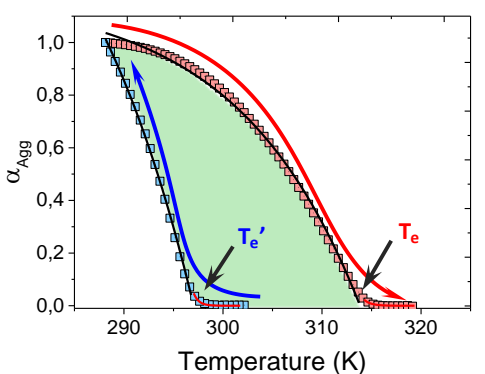

$\mathbf{F}$

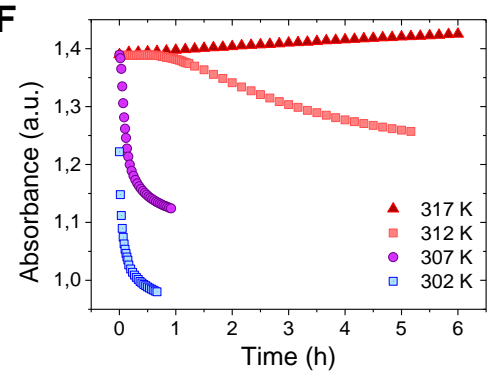

Figure 3. Characteristic supramolecular polymerization data of TATA molecules: $($ A $)$ Temperature-dependent UV-Vis absorption spectra of $(\mathbf{S})$-TATA $(c=$ $0.5 \mathrm{mM}$ in toluene) recorded during a cooling process between $50^{\circ} \mathrm{C}$ and $20^{\circ} \mathrm{C}$; (B) Evolution of the absorption at $315 \mathrm{~nm}$ as a function of the temperature plotted from (A); (C) Temperature dependence of the degree of aggregation ( $\square_{\text {Agg }}$ ) of (S)-TATA at a concentration of $0.1 \mathrm{mM}$ in toluene, and calculated from the temperature dependent UV data recorded at $315 \mathrm{~nm}$, obtained during the cooling (blue squares) and heating (red squares) processes. Solid lines represent the cooperative polymerization fit in the nucleation (red) and the elongation (black) regimes; (D) Evolution of the total concentration of molecules $C_{T}$ as a function of elongation temperature $T_{e}$ for (S)-TATA in the cooling (blue squares) and the heating (red squares) regimes. Dashed lines represent the nonlinear fit; $(\mathbf{E})$ Evolution of the natural logarithm of the reciprocal concentration $C_{T}$ as a function of the reciprocal $T_{e}$ during the heating process. Solid lines represent the linear fit of the experimental data; $(\mathbf{F})$ Evolution of the absorption intensity recorded at $315 \mathrm{~nm}$ for $0.21 \mathrm{mM}$ solutions of (S)-TATA in toluene measured at different temperatures. At $317 \mathrm{~K}$, the gradual increase of the absorption intensity is an artefact due to the slow evaporation of toluene from the cuvette over the time of the experiment.

This observation is also in agreement with previous studies in which the nucleation step of the polymerization process is triggered by the light-induced formation of flat triarylammonium radicals. ${ }^{[36]}$

We then looked at the influence of the structure and length of the side alkyl chains and solvent composition on the selfassembling behavior of TATAs. Melting curves were recorded from temperature-dependent UV experiments at a wavelength of $315 \mathrm{~nm}$ for $\left(\mathbf{C}_{9}\right)$ - and $\left(\mathbf{C}_{14}\right)$-TATAs in toluene, and for $(\mathbf{S})$-TATA in a mixture of toluene/methylcyclohexane $(\mathrm{MCH}) 1: 1 \mathrm{v} / \mathrm{v}$. In all cases, the data could be fitted with the cooperative model used previously, and a similar thermal hysteresis - characterized by two elongation temperatures $T_{e}$ ' and $T_{e}$ - was observed (Figure S15). For the same concentration in toluene, the lowest $T_{e}$ is observed for (S)-TATA, while (C) $\mathbf{C}_{9}$-TATA is characterized by the highest $T_{e}$ (Figure 3E,F). This effect can be explained by the less compact packing of the branched alkyl chains, in comparison to the linear ones. Additionally, for (S)-TATA, the elongation temperatures in the heating $\left(T_{e}\right)$ and cooling $\left(T_{e}\right)$ processes along with the elongation enthalpy $\Delta H_{e}$ were found to increase in a mixture of toluene/ $\mathrm{MCH}$ compared to pure toluene at a concentration of $0.1 \mathrm{mM}$ (Table S3). These results clearly indicate that the supramolecular polymer made of (S)-TATA is thermodynamically less stable in toluene, probably because of lower polarity of the toluene/ $\mathrm{MCH}$ mixture.

Finally, we evaluated how temperature can influence the kinetics of the supramolecular polymerization process. As reported by Würthner et al., ${ }^{[15]}$ the existence of a thermal hysteresis implies that the monomers can be kinetically inactivated between $T_{e}$ and $T_{e}^{\prime}$, i.e. that the supramolecular polymerization can be retarded depending on the temperature at which the self-assembling process is monitored. To verify this hypothesis, we followed the evolution of the absorbance of (S)-TATA with time at different temperatures (Figure 3F). For a $0.21 \mathrm{mM}$ solution, we found that (a) for temperatures below $T_{e}^{\prime}$, polymerization occurs immediately and thermodynamic equilibrium is reached within around 1 hour, and that (b) for temperatures between $T_{e}$ and $T_{e}$, the aggregation of TATA molecules is delayed with increasing time as the temperature of polymerization approaches $T_{e}$. For instance, at $317 \mathrm{~K}$, no polymerization was observed over the 6 hours of the experiment. These experiments also show that temperature can be used as a trigger to kinetically bias the supramolecular polymerization process towards sigmoidal growths. ${ }^{[36]}$

\section{Influence of the Cooling Rate on the Hierarchical Ordering}

We then studied the chirality of the aggregation process of (S)-TATA by using temperature-dependent CD spectroscopy. We focused on the self-assembly behavior in toluene at different concentrations and for different cooling rates between $50^{\circ} \mathrm{C}$ and $20^{\circ} \mathrm{C}$. In all experiments the linear dichroism (LD) was also measured and in all cases no significant linear dichroism was observed (i.e. LD was never higher than one thousandth of the CD signal). 
A
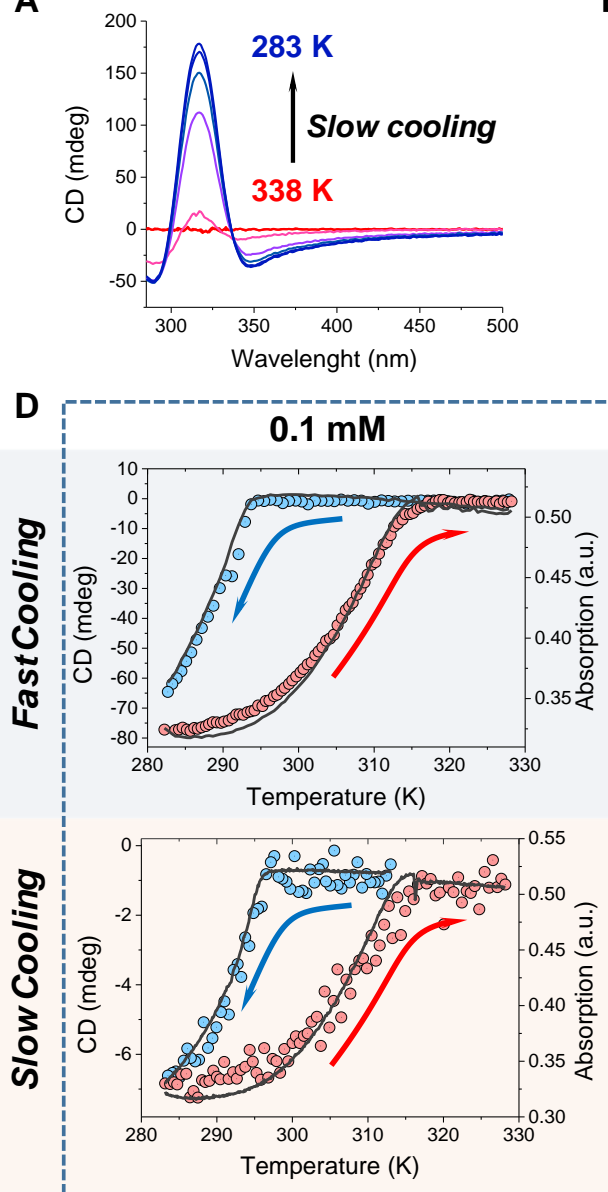

B
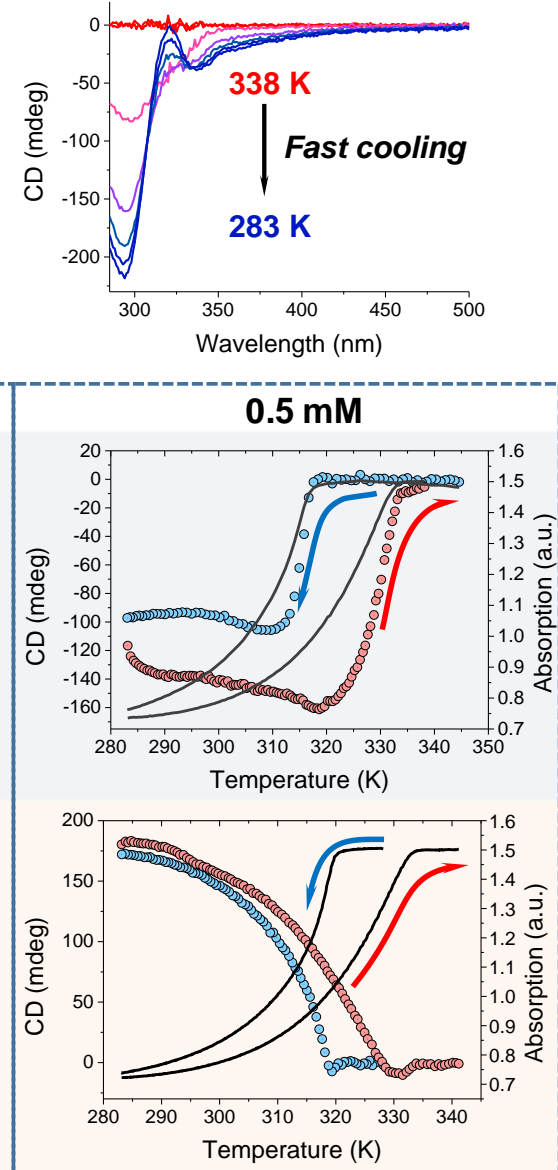

C

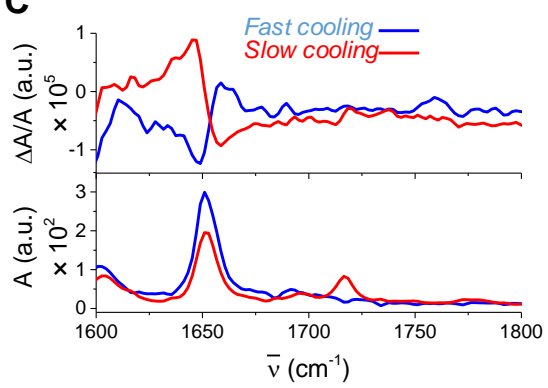

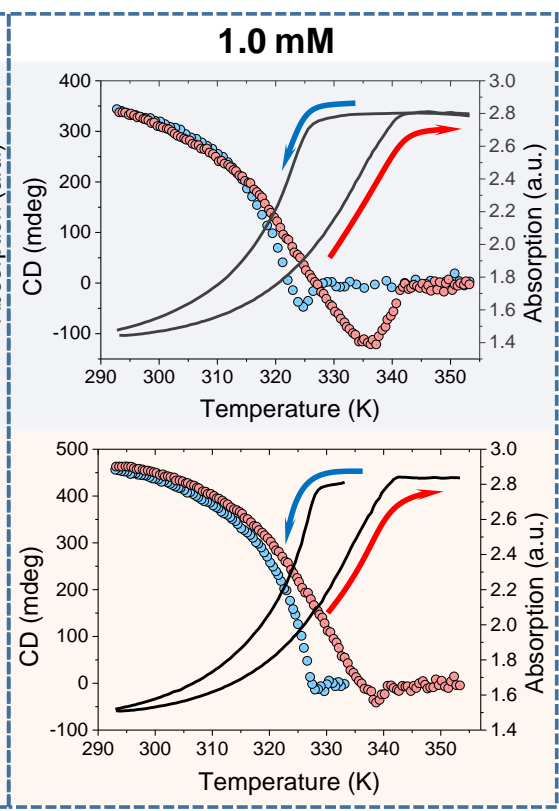

Figure 4. (A-B) Evolution of CD spectra for $0.5 \mathrm{mM}$ solutions of (S)-TATA in toluene and for different cooling rates: (A) Slow cooling (1 K·min $\left.{ }^{-1}\right)$ and (B) fast cooling $\left(10 \mathrm{~K} \cdot \mathrm{min}^{-1}\right)$ regimes; (C) Vibrational Absorption (bottom) and Vibrational Circular Dichroism (top) spectra recorded for $0.5 \mathrm{mM}$ solutions of (S)TATA in toluene under slow cooling (red line) and fast cooling (blue line) regimes; (D) Temperature-dependent CD (blue and red circles) and UV (grey solid lines) curves recorded for (S)-TATA in toluene at various concentrations and for different cooling regimes (see also Figure S19). CD and UV intensities were both recorded at $315 \mathrm{~nm}$. Blue and red colors correspond to the cooling and heating processes, respectively.

We first monitored the evolution of the CD signal at a fixed concentration of $0.5 \mathrm{mM}$ and for a cooling rate of $1 \mathrm{~K} \cdot \mathrm{min}^{-1}$ (that will be referred hereafter as "slow cooling"). The CD signal showed increased intensities for the positive maximum at $318 \mathrm{~nm}$ and for the negative one at $344 \mathrm{~nm}$ (Figure 4A). Surprisingly, when a hot solution of (S)-TATA was cooled with a rate of $10 \mathrm{~K} \cdot \mathrm{min}^{-1}$ (that will be referred hereafter as "fast cooling"), the CD signal displayed an increasing negative intensity maximum at $292 \mathrm{~nm}$, together with a second increasing negative intensity at $344 \mathrm{~nm}$ (Figure 4B). Importantly, no signal corresponding to molecular CD was observed at high temperature, probably because of the high dynamics of TATA propeller-like chirality in solution. However, upon aggregation, the freezing of the propeller conformation results in the appearance of a molecular-propeller contribution to the CD spectrum. It is also expected that the aggregation of (S)-TATA in such hierarchical supramolecular systems should produce a complex CD signal resulting from the combination of (i) molecular CD, (ii) first order aggregationinduced CD (i.e. CD caused by the spatial organization of chromophores in the primary aggregates, such as single chain polymers here for instance), and (iii) aggregation-induced $C D$ of higher orders (i.e. CD caused by further aggregation of the single chain polymers into superstructures, such as chiral bundle of fibers and superhelices for instance, and as observed in the literature for a few other systems). ${ }^{[60,61]}$ At the same concentration of $0.5 \mathrm{mM}$, we were also able to perform VCD experiments (Figure 4C) (see details in Supporting Information (SI), Section S2.7). Interestingly, a clear inversion of the bisignate peak for the amide-I band at $1650 \mathrm{~cm}^{-1}$ was observed (-/+ for fast cooling, and +/- for slow cooling), in line with the CD measurements. The results reported in Figure $4 \mathrm{~A}-\mathrm{C}$ thus suggest the presence of two self-assembly pathways that diverge between the slow and fast cooling regimes and that lead to distinct thermodynamic and kinetic supramolecular structures, respectively. In addition, the stability of the CD signal (sign and intensity) remains for at least 2 days for both 0.1 and $0.5 \mathrm{mM}$ concentrations and fast cooling, indicating the high stability of the kinetic self-assembly at room temperature, a situation not yet reported in the literature and of particular fundamental and practical interests.

To probe further our hypothesis, we studied how concentration influences the kinetics of aggregation for the two cooling regimes (see Figure 4D (for 0.1, 0.5, and $1 \mathrm{mM}$ ); and Figure $\mathrm{S} 19$ (for $0.25,0.32$, and $0.75 \mathrm{mM}$ )). On the one hand, at all concentrations and cooling rates, UV monitoring of the polymerization process at $315 \mathrm{~nm}$ confirmed the presence of a thermal hysteresis with $T_{e}$ and $T_{e}^{\prime}$ increasing with increasing concentrations (Figures $3 C, \mathrm{D}$, and S11,13-15). On the other hand, and although monitoring the CD signal of (S)-TATA solutions in toluene confirmed the nucleation growth mechanism of the polymerization (Figure S20), the data demonstrate in addition the presence of different self-assembling pathways depending on the cooling rate. 
Negative CD at $315 \mathrm{~nm}$ occurs mainly in relatively diluted solutions ([(S)-TATA $] \leq 0.32 \mathrm{mM})$ in the slow cooling, and up to moderate concentrations $([(S)-T A T A] \leq 0.75 \mathrm{mM})$ in the fast cooling conditions. Positive $C D$ at the same wavelength is observed mainly at high concentrations $([(S)-T A T A]=1.0 \mathrm{mM})$ in the fast cooling, and at moderate and high concentrations $(0.5 \mathrm{mM} \leq$ $[(S)-T A T A] \leq 1.0 \mathrm{mM}$ ) in the slow cooling conditions. These observations suggest that, at low concentrations and for fast cooling rate, primary chiral assemblies are formed corresponding to mono-columnar TATA fibers. Interestingly, at slow cooling rates, a mixture of single fibrils with higher order aggregates such as superhelical structures are possibly obtained (as the intensity of the negative signal is only of $7 \mathrm{mdeg}$, compared to the 70 mdeg for the fast cooling). At a higher concentration of $1 \mathrm{mM}$, primary fibers self-organize into higher order aggregates such as superhelical structures irrespective of the cooling rate. Another very interesting and important results highlighted at $1 \mathrm{mM}$, especially for the fast cooling regime, is the presence of a non-monotonic variation of the sign of the $C D$ as a function of temperature, revealing first a negative signal that turns into a positive one upon cooling, as well as the reappearance of a negative signal before going to 0 upon heating. This memory effect strongly suggests that the superhelical structures are made from single helices, and that their primary helical structure is not lost when forming the superstructures. In the medium concentration range $(0.5 \mathrm{mM})$, the $C D$ increases to positive values of about 150 mdeg during slow cooling experiments, whereas in fast cooling conditions, the CD decreases to negative values of about -100 mdeg, and then remains constant. Considering that disassembly is rather improbable below $T_{e}{ }^{\prime}$, we believe that this plateau is related to the co-existence of single fibers along with some superstructures, which add a positive contribution to the CD. This is also in agreement with the intensity of the negative CD signal, which is not as high as expected from the experiment performed at 0.1 $\mathrm{mM}$.

In order to confirm definitely the existence of such hierarchical self-assembly pathways, and to assign their absolute configuration, we performed AFM imaging on enantiopure (S)-TATA solutions after either slow or fast cooling. AFM micrographs of self-assemblies, obtained from a $0.1 \mathrm{mM}$ solution, reveal the sole presence of single fibers with a $P$ helicity that can slightly coagulate by lateral aggregation (Figures $5 \mathrm{~A}, \mathrm{~B})$. In a striking difference, for high concentrations (1 mM), only large $M$ helical bundles were observed by AFM (Figure S6B,C). For medium concentrations of $0.5 \mathrm{mM}$ (Figures 5C-F and S6D,E), the observations vary depending on the cooling regimes. Interestingly, for the fast cooling process, single $P$-helices with some coagulation between them are formed (Figure 5C).
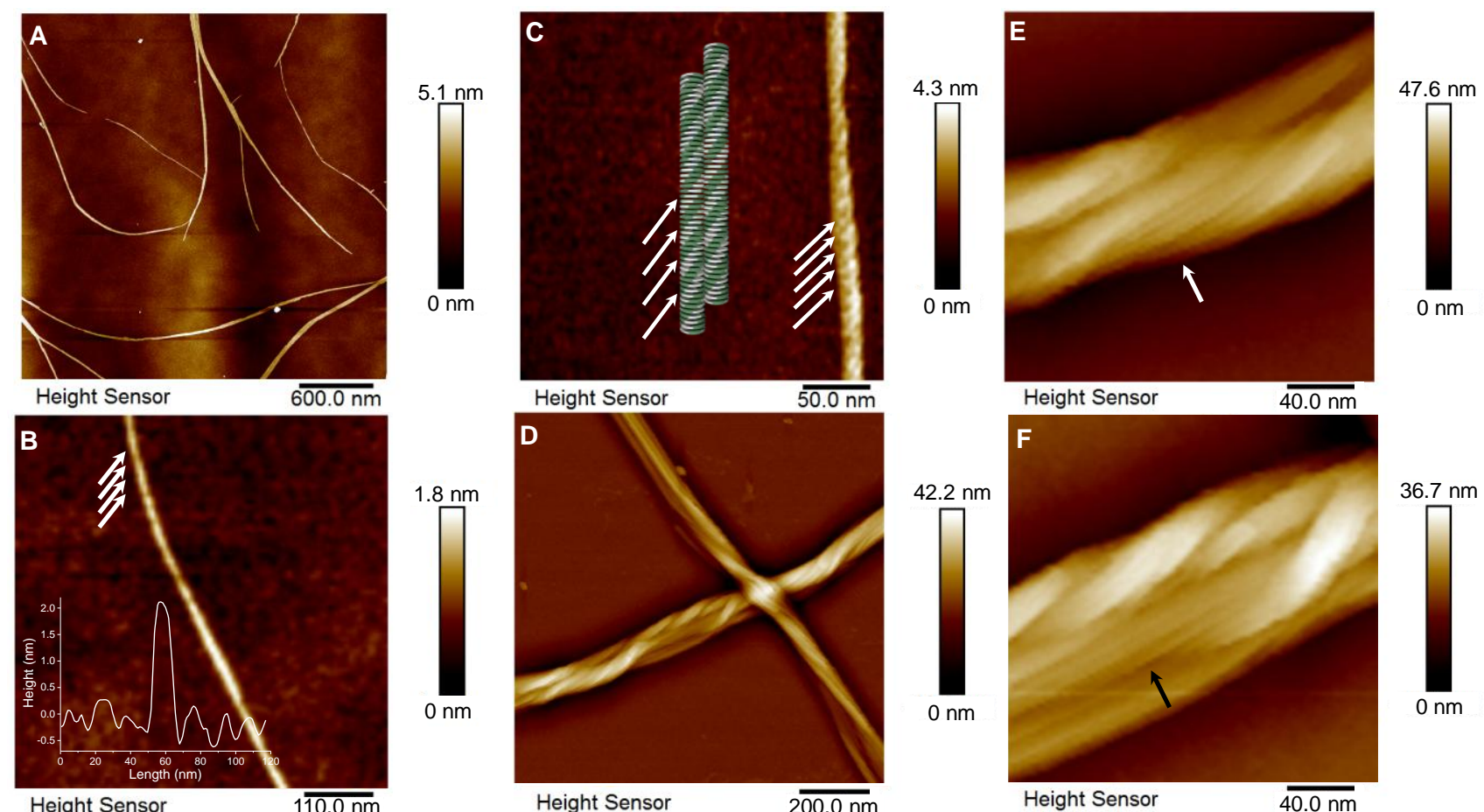

Figure 5. (A-B) AFM height image of (S)-TATA self-assemblies from a $0.1 \mathrm{mM}$ solution in toluene and (B) of a single fiber with a $P$-helicity, (inset shows its height profile); (C-F) AFM height image of (S)-TATA self-assemblies from $0.5 \mathrm{mM}$ solutions in toluene. (C) Fast cooling regime (10 K-min ${ }^{-1}$ ). (D-F) Slow cooling regime $\left(1 \mathrm{~K} \cdot \mathrm{min}^{-1}\right)$. In $4 \mathrm{E}, \mathrm{F}$, which represent magnified regions of $4 \mathrm{D}$, where the presence of only single $P$-helices in larger $M$-superhelices $(i . e$. $P$ helix $\subset M$-superhelix) is identified (see for instance the regions pointed by the arrows, and an extended micrograph in the SI).

For slow cooling, larger bundles appear with a global $M$-superhelix arrangement but internally composed of individual $P$-helices (Figure D-F). Such an important morphological difference is consistent with the various spectroscopic responses observed by CD. In addition, DFT calculations combined with VCD experiments (Figure 4C), are in agreement with the presence of a bisignate $(-/+)$ peak for a $P$ conformation, as observed for fast cooling, and with the presence of a bisignate (+/-) peak for a $M$ conformation, as observed for slow cooling (see details in Supporting Information (SI), Section S2.7).

To explain these experimental data we propose that, while following a similar primary nucleation step to lead to short monocolumnar stacks (Figure 6 steps 1-3 - grey circles), (S)-TATA primary fibrils can then give rise to different hierarchical structures depending on the concentration and cooling rates between two identical temperatures $\left(50^{\circ} \mathrm{C}\right.$ to $\left.20^{\circ} \mathrm{C}\right)$. At low 
concentrations, independently of the cooling rate, the growth of single fibers with a $P$ helicity and coagulation of a small number of these fibers is the dominant process characterized by a negative CD signal and a -/+ bisignate VCD signal (Figure 6 steps 4 5 - blue circles). At high concentrations, independently of the cooling rate, an additional level of self-assembly takes place from the short monocolumnar stacks (with a $P$ helicity) that consists of the formation of polyfibrillar nuclei that further enter in a superhelical growth regime. The positive CD signal and +/- bisignate VCD signals observed result from such highly twisted bundles of supramolecular fibers with a $M$ helicity (Figure 6 steps 4'-5' - red circles). Finally, at medium concentrations, the cooling rate can drive the system towards one of the other self-assembly pathways. Very importantly, and as shown by the memory effect on step 3 (for instance well seen in Figure 4D, fast cooling at $1 \mathrm{mM}$ ), the primary aggregates have identical columnar packing for both cooling regimes (i.e. $P$ helices). Conversely, beyond the primary polymerization process, the hierarchy of these supramolecular structures can be modified by the cooling rate of the environment, which influences the secondary nucleation step.

\section{Conclusion}

We have elucidated the hierarchical self-assembly mechanism of a series of TATA molecules using a combination of spectroscopic techniques together with microscopy experiments and DFT calculations. We have first demonstrated that TATAs self-assemble according to a cooperative nucleation and growth polymerization process. The presence of a strong thermal hysteresis between the assembly and disassembly processes is related to the existence of a kinetic barrier during the aggregation process, thus offering the possibility to delay the nucleation process and to reach sigmoidal growth for temperatures comprised between $T_{e}$ and $T_{e}$ '. This behavior relates here to the particular propeller shape of the TATA molecules. It induces strong entropic and conformational contributions to the self-assembly process which relates to $I$ ) the breakage of the intramolecular rotation at the nitrogen center of the $C_{3}$-symmetric TATA, and to ii) the heterochiral mismatch of their $\Delta$ and $\Lambda$ conformers in the stacking of the columnar polymers. We have also unraveled the presence of divergent chiral self-assembly pathways that can take place at a similar concentration and range of temperature but for different cooling rates of the system. Kinetic analysis of the CD melting curves, interpretation of VCD bisignate bands, as well as AFM imaging here show together that the difference of chirality is related to the formation of structures of higher hierarchy (i.e. superhelices) which readily form upon slow cooling. Such a large structural change obtained from such a small thermal effect is of particular fundamental interest for gaining knowledge and control over complex self-assembly processes. This unprecedented observation of a hierarchical bifurcation is possible because the system shows a peculiar novelty compared to the other systems published so far in the literature, as the kinetic product (single $P$-helix) is thermally stable for a long time without conversion to the thermodynamic product $(P$-helix $\subset M$-superhelix), so as it can be properly isolated and characterized. The reason of this stability relates to the very low kinetic lability of TATA molecules in the primary stacks, as well as to their locked conformation as $P$ propellers in the single helix (as shown by the strong memory effect deciphered here). This feature is also of potential practical interest for finetuning the physical properties of functional materials of these systems. ${ }^{[9]}$

Overall, these results highlight that pathway complexity ${ }^{[30,31]}$ in supramolecular polymerization can be also encountered in systems that produce similar primary nucleation steps and primary growths, but which diverge in their secondary or higher organizational order (and such as it is found in nature, for instance with the secondary nucleation involved in the formation of $\beta$ amyloids). ${ }^{[62]}$ Therefore, they enrich the understanding of supramolecular polymerization mechanisms towards stepwise hierarchical structures that involve increasing levels of spatial and temporal organizations, and as encountered in complex living systems. 

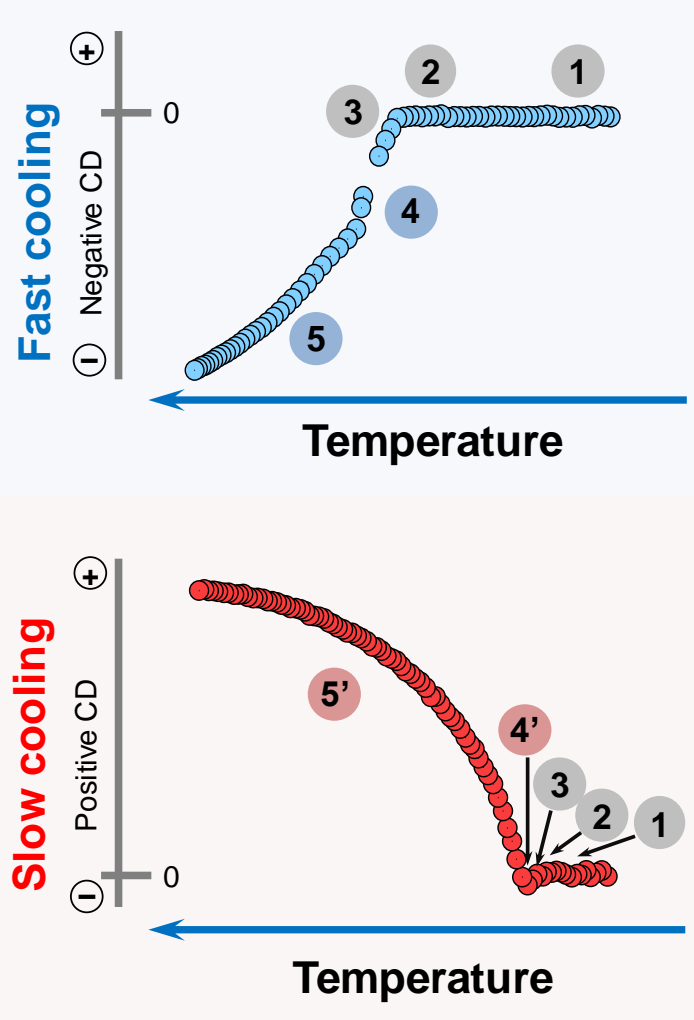

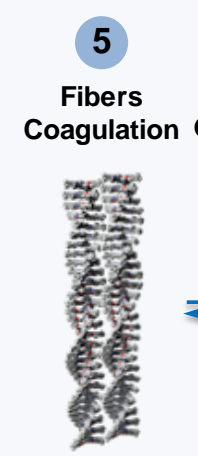

4 P-helical Growth Regime
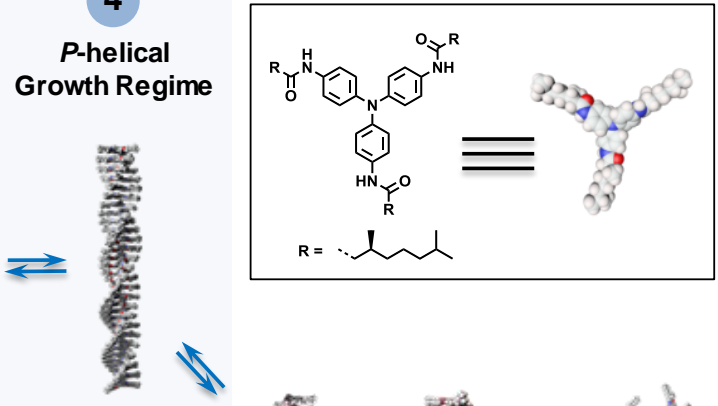

\section{4}
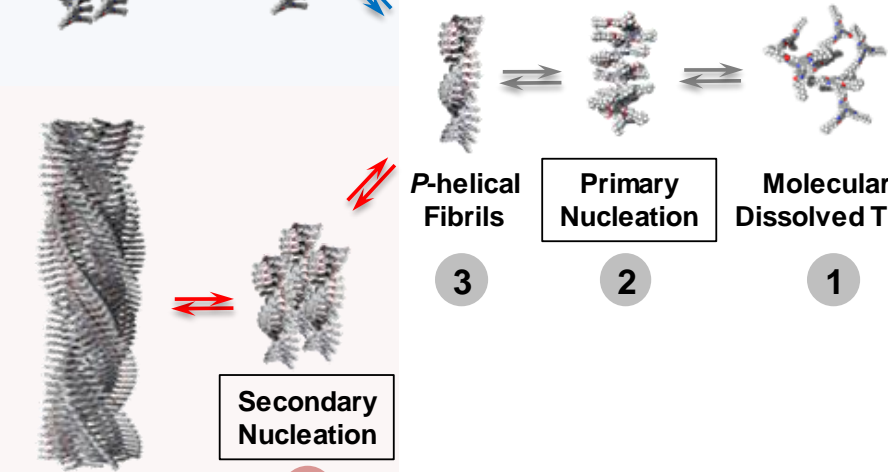

M-Superhelical Growth regime

5'

Figure 6. Schematic representation of the two main self-assembly pathways for (S)-TATA molecules depending of the cooling rate at a typical concentration of $0.5 \mathrm{mM}$ in toluene. The mechanism of primary nucleation is shared by both pathways up to the formation of $P$-helical fibrils (3), but then differs to evolve toward a primary growth regime of $P$-helical fibers (for fast cooling) or toward a secondary nucleation and growth regime of $M$-superhelical fibers (i.e. $P$-helix $\subset M$-superhelix) (for slow cooling).

\section{Acknowledgements}

The research leading to these results has also received funding from the European Research Council under the European Community's Seventh Framework Program (FP7/2007-2013)/ERC Starting Grant Agreement No. 257099 (N.G.). This work was also supported by funds from ITN READ, PITN-GA-2011-289723 (fellowship to A.O.). M.K. and W.J.B. acknowledge funding from the Netherlands Organisation for Scientific Research (NWO) in the framework of the Fund New Chemical Innovations (NWO Project Nr. 731.014.209). We wish to thank the international center for Frontier Research in Chemistry (icFRC), the Laboratory of Excellence for Complex Systems Chemistry (LabEx CSC), and the Institut Universitaire de France (IUF) for financial support. We also acknowledge the Electron Microscopy Facility of the Institut Charles Sadron.

Keywords: supramolecular polymers $\bullet$ hierarchical self-assembly $\bullet$ pathway complexity $\bullet$ organogelators

[1] E. Yashima, N. Ousaka, D. Taura, K. Shimomura, T. Ikai, K. Maeda, Chem. Rev. 2016, 116, 13752-13990.

[2] M. Liu, L. Zhang, T. Wang, Chem. Rev. 2015, 115, 7304-7397.

[3] T. F. A. De Greef, M. M. J. Smulders, M. Wolffs, A. P. H. J. Schenning, R. P. Sijbesma, E. W. Meijer, Chem. Rev. $2009,109,5687-5754$.

[4] A. Ciferri, Supramolecular Polymers, CRC Press, 2005.

[5] L. Brunsveld, B. J. B. Folmer, E. W. Meijer, R. P. Sijbesma, Chem. Rev. 2001, 101, 4071-4098.

[6] A. Jain, S. J. George, Mater. Today 2015, 18, 206-214.

[7] E. Moulin, E. Busseron, N. Giuseppone, in RSC Smart Mater., 2015, pp. 1-52.

[8] E. Moulin, J.-J. Cid, N. Giuseppone, Adv. Mater. 2013, 25, 477-487.

[9] E. Busseron, Y. Ruff, E. Moulin, N. Giuseppone, Nanoscale 2013, 5, 7098-7140.

[10] A. P. H. J. Schenning, E. W. Meijer, Chem. Commun. 2005, 3245-3258.

[11] K.-T. Wong, D. M. Bassani, NPG Asia Mater. 2014, 6, e116.

[12] S. S. Babu, V. K. Praveen, A. Ajayaghosh, Chem. Rev. 2014, 114, 1973-2129.

[13] S. I. Stupp, L. C. Palmer, Chem. Mater. 2014, 26, 507-518.

[14] D. González-Rodríguez, A. P. H. J. Schenning, Chem. Mater. 2011, 23, 310-325.

[15] S. Ogi, V. Stepanenko, K. Sugiyasu, M. Takeuchi, F. Würthner, J. Am. Chem. Soc. 2015, 137, 3300-3307.

[16] T. Fukui, S. Kawai, S. Fujinuma, Y. Matsushita, T. Yasuda, T. Sakurai, S. Seki, M. Takeuchi, K. Sugiyasu, Nat. Chem. 2017, 9, 493-499.

[17] S. Ogi, C. Grzeszkiewicz, F. Würthner, Chem. Sci. 2018, 9, 2768-2773.

[18] B. Kemper, L. Zengerling, D. Spitzer, R. Otter, T. Bauer, P. Besenius, J. Am. Chem. Soc. 2018, 140, 534-537. 
[19] J. Kang, D. Miyajima, T. Mori, Y. Inoue, Y. Itoh, T. Aida, Science 2015, 347, 646-651.

[20] S. Ogi, K. Sugiyasu, S. Manna, S. Samitsu, M. Takeuchi, Nat. Chem. 2014, 6, 188-195

[21] W. Wagner, M. Wehner, V. Stepanenko, S. Ogi, F. Würthner, Angew. Chem. Int. Ed. 2017, 56, 16008-16012.

[22] K. Zhang, M. C.-L. Yeung, S. Y.-L. Leung, V. W.-W. Yam, Proc. Natl. Acad. Sci. 2017, 114, 11844-11849.

[23] B. Adelizzi, A. Aloi, A. J. Markvoort, H. M. M. Ten Eikelder, I. K. Voets, A. R. A. Palmans, E. W. Meijer, J. Am. Chem. Soc. 2018, 140, 7168-7175.

[24] J. Xu, H. Zhou, Q. Yu, I. Manners, M. A. Winnik, J. Am. Chem. Soc. 2018, 140, 2619-2628.

[25] U. Tritschler, S. Pearce, J. Gwyther, G. R. Whittell, I. Manners, Macromolecules 2017, 50, 3439-3463.

[26] M. E. Robinson, A. Nazemi, D. J. Lunn, D. W. Hayward, C. E. Boott, M.-S. Hsiao, R. L. Harniman, S. A. Davis, G. R. Whittell, R. M. Richardson, et al., ACS Nano 2017, 11, 9162-9175.

[27] D. Görl, X. Zhang, V. Stepanenko, F. Würthner, Nat. Commun. 2015, 6, 7009.

[28] C. Kulkarni, E. W. Meijer, A. R. A. Palmans, Acc. Chem. Res. 2017, 50, 1928-1936.

[29] J. Cui, A. Liu, Y. Guan, J. Zheng, Z. Shen, X. Wan, Langmuir 2010, 26, 3615-3622.

[30] P. A. Korevaar, T. F. A. de Greef, E. W. Meijer, Chem. Mater. 2014, 26, 576-586.

[31] P. A. Korevaar, S. J. George, A. J. Markvoort, M. M. J. Smulders, P. A. J. Hilbers, A. P. H. J. Schenning, T. F. A. De Greef, E. W. Meijer, Nature 2012, 481, 492-496.

[32] E. Moulin, J. J. Armao, N. Giuseppone, Acc. Chem. Res. 2019, 52, 975-983.

[33] J. J. Armao, M. Maaloum, T. Ellis, G. Fuks, M. Rawiso, E. Moulin, N. Giuseppone, J. Am. Chem. Soc. 2014, 136, 11382-11388.

[34] J. J. Armao, I. Nyrkova, G. Fuks, A. Osypenko, M. Maaloum, E. Moulin, R. Arenal, O. Gavat, A. Semenov, N. Giuseppone, J. Am. Chem. Soc. 2017, 139, 2345-2350.

[35] E. Moulin, F. Niess, M. Maaloum, E. Buhler, I. Nyrkova, N. Giuseppone, Angew. Chem. Int. Ed. 2010, 49, 6974-6978.

[36] I. Nyrkova, E. Moulin, J. J. Armao, M. Maaloum, B. Heinrich, M. Rawiso, F. Niess, J.-J. Cid, N. Jouault, E. Buhler, et al., ACS Nano 2014, 8, 1011110124.

[37] A. Wolf, E. Moulin, J. J. Cid Martín, A. Goujon, G. Du, E. Busseron, G. Fuks, N. Giuseppone, Chem. Commun. 2015, 51, 4212-4215.

[38] S. Schneider, E.-D. E.-D. Licsandru, I. Kocsis, A. Gilles, F. Dumitru, E. Moulin, J. Tan, J.-M. J.-M. Lehn, N. Giuseppone, M. Barboiu, J. Am. Chem. Soc. 2017, 139, 3721-3727.

[39] V. Faramarzi, F. Niess, E. Moulin, M. Maaloum, J.-F. Dayen, J.-B. Beaufrand, S. Zanettini, B. Doudin, N. Giuseppone, Nat. Chem. 2012, 4, 485-490.

[40] E. Busseron, J.-J. Cid, A. Wolf, G. Du, E. Moulin, G. Fuks, M. Maaloum, P. Polavarapu, A. Ruff, A.-K. Saur, et al., ACS Nano 2015, 9, 2760-2772.

[41] T. K. Ellis, M. Galerne, J. J. Armao, A. Osypenko, D. Martel, M. Maaloum, G. Fuks, O. Gavat, E. Moulin, N. Giuseppone, Angew. Chem. Int. Ed. 2018, 57, 15749-15753.

[42] A. T. Haedler, K. Kreger, A. Issac, B. Wittmann, M. Kivala, N. Hammer, J. Köhler, H.-W. Schmidt, R. Hildner, Nature 2015, 523, 196-199.

[43] J. J. Armao, Y. Domoto, T. Umehara, M. Maaloum, C. Contal, G. Fuks, E. Moulin, G. Decher, N. Javahiraly, N. Giuseppone, ACS Nano 2016, 10, 2082-2090.

[44] J. J. Armao, P. Rabu, E. Moulin, N. Giuseppone, Nano Lett. 2016, 16, 2800-2805.

[45] T. Kim, T. Mori, T. Aida, D. Miyajima, Chem. Sci. 2016, 7, 6689-6694.

[46] J. Kim, J. Lee, W. Y. Kim, H. Kim, S. Lee, H. C. Lee, Y. S. Lee, M. Seo, S. Y. Kim, Nat. Commun. 2015, 6, 6959.

[47] K. Y. Kim, C. Kim, Y. Choi, S. H. Jung, J. H. Kim, J. H. Jung, Chem. Eur. J. 2018, 24, 11763-11770.

[48] B. Adelizzi, I. A. W. Filot, A. R. A. Palmans, E. W. Meijer, Chem. Eur. J. 2017, 23, 6103-6110.

[49] B. Adelizzi, A. Aloi, N. J. Van Zee, A. R. A. Palmans, E. W. Meijer, I. K. Voets, ACS Nano 2018, 12, 4431-4439.

[50] A. T. Haedler, S. C. J. Meskers, R. H. Zha, M. Kivala, H.-W. Schmidt, E. W. Meijer, J. Am. Chem. Soc. 2016, 138, 10539-10545

[51] P. J. M. Stals, M. M. J. Smulders, R. Martín-Rapún, A. R. A. Palmans, E. W. Meijer, Chem. Eur. J. 2009, 15, $2071-2080$.

[52] P. J. M. Stals, J. C. Everts, R. de Bruijn, I. A. W. Filot, M. M. J. Smulders, R. Martín-Rapún, E. A. Pidko, T. F. A. de Greef, A. R. A. Palmans, E. W. Meijer, Chem. Eur. J. 2010, 16, 810-821.

[53] K. Hanabusa, C. Koto, M. Kimura, H. Shirai, A. Kakehi, Chem. Lett. 1997, 429-430.

[54] R. M. Silverstein, F. X. Webster, D. J. Kiemle, D. L. Bryce, Spectrometric Identification of Organic Compounds, Wiley, 2014

[55] M. M. J. Smulders, A. P. H. J. Schenning, E. W. Meijer, J. Am. Chem. Soc. 2008, 130, 606-611.

[56] F. García, P. M. Viruela, E. Matesanz, E. Ortí, L. Sánchez, Chem. Eur. J. 2011, 17, 7755-7759.

[57] A. J. Markvoort, H. M. M. ten Eikelder, P. A. J. Hilbers, T. F. A. de Greef, E. W. Meijer, Nat. Commun. 2011, 2, 509.

[58] M. M. J. Smulders, M. M. L. Nieuwenhuizen, T. F. A. De Greef, P. Van der Schoot, A. P. H. J. Schenning, E. W. Meijer, Chem. Eur. J. 2010, 16, 362-367.

[59] P. Jonkheijm, P. van der Schoot, A. P. H. J. Schenning, E. W. Meijer, Science 2006, 313, 80-3.

[60] P. J. M. Stals, P. A. Korevaar, M. A. J. Gillissen, T. F. A. de Greef, C. F. C. Fitié, R. P. Sijbesma, A. R. A. Palmans, E. W. Meijer, Angew. Chem. Int Ed. 2012, 51, 11297-11301.

[61] M. Hifsudheen, R. K. Mishra, B. Vedhanarayanan, V. K. Praveen, A. Ajayaghosh, Angew. Chem. Int. Ed. 2017, 56, 12634-12638.

[62] V. Foderà, F. Librizzi, M. Groenning, M. van de Weert, M. Leone, J. Phys. Chem. B 2008, 112, 3853-3858. 